\title{
Practices of media sport: everyday experience and audience innovation
}

James Meese \& Aneta Podkalicka

\section{Bios}

James Meese is a lecturer in Communications at the University of Technology, Sydney.

Aneta Podkalicka is a researcher at the Swinburne Institute for Social Research, Swinburne University, Melbourne.

\begin{abstract}
Media sport has a long history as a significant site of media innovation and existing work in media and cultural studies has explored how media sport, technological innovation and regulatory frameworks interact. However, this work tends to often focus on how major actors such as broadcasting organisations, sporting bodies and telecommunications companies mediate sport. As a complementary strategy to this 'top-down' analysis, we approach media sport through the lens of practice, which allows us to understand everyday forms of engagement with and consumption of media sport in a clearer fashion. The paper analyses existing policy discourses and social commentaries centred on the targeted 'high-quality' or 'high-tech technological innovation', and argues that users of sports media are also motivated by series of cultural rewards and varied trade-offs that do not map neatly onto industrial categories of quality or media consumption trends.
\end{abstract}




\section{Introduction}

Sport is big business on the field and on the screen. A range of academic literature has recognised its importance as a media text, a representational and identity shaping cultural sphere (Majoribanks and Farquharson, 2011; Hartley and McKee, 2000), and a dynamic media industry. Analyses of sports media drawing on political economy have been particularly influential (Maguire, 1993; Rowe, 2004; Hutchins and Rowe, 2009, 2012; Whitson, 1998), focussing on major actors like broadcast and regulatory organisations, sporting bodies, and telecommunications companies. Researchers have also engaged with the cultural impact of increasingly corporatised sporting codes (see Miller et al., 2001; Miller, 2010; Rowe, 2004; Whannel, 2001, 2008), providing a useful guide to a complicated environment where sporting professionals are paid millions of dollars, sports broadcasting rights are still the 'jewels' in broadcast network 'crowns', and where sports fandom operates as an influential cultural practice.

This paper offers a practice-oriented perspective in order to analyse how sports media operates in a post-broadcast era. It is a perspective that complements current political economy-oriented analyses of sports media, shifting emphasis from numbers and figures, regulatory frameworks and high-level technological innovations to a focus on everyday engagements with media sport. Drawing on conceptual tools from anthropology and sociology, this approach connects with a theoretical and methodological direction advanced by Pertierra and Turner (2013), who argue that recent accounts of the post-broadcast media space inadequately attend to the diversity and local specificities of consumption practices around television.

This paper begins with a discussion of the existing literature on media sport. We proceed by presenting our approach that centres on theories of media practice (see Couldry, 2004, 2012; 
Postill, 2010) and interdisciplinary accounts of media in the post-broadcast era. This practiceoriented approach is applicable to media studies research in general, but media sport scholarship in particular would benefit from an increased focus on everyday media practices, where digital production and consumption are ceaselessly valued, tested and realised in practice. To illustrate our argument, we present several contemporaneous examples of the everyday media practices of sport, drawing on publicly accessible content online and existing

research. While further empirical research is needed to explore the scale and significance of these practices, we believe that the examples presented are suggestive of discernible patterns and principles occurring at the 'micro' level of media cultures, thereby presenting sports scholars with important avenues for further analysis.

\section{The state of play: sports media scholarship from the 1980s to today}

Existing academic studies of sport have provided a valuable outline of the numerous interactions and complex linkages that operate between the spheres of media and sport. Nascent research on the sport/media nexus was conducted through a critical sociological paradigm largely interested in the reproduction and legitimisation of masculine, nationalistic and corporate ideologies through media representation of sport (McKay, 1991). This research examined existing structures of the industrial media, and the extent to which particular ideologies and myth-making are supported by sport as both a cultural practice and media text. Alternative research agendas were also set out by edited collections such as Media, Sports and Society (Wenner, 1989) and Sport and Leisure: Trends in Australian Popular Culture (Rowe and Lawrence, 1990) that called on scholars to pay direct attention to the relationship between media and sport, treating the latter as a business and attending to the intricacies of the mediated sports production complex. 
Scholars have responded to this agenda in earnest and a significant number of scholarly works have directly attended to the business of 'media sport' and globalisation's role in transnational economies (for example, Miller et al., 2001; Maguire, 1993; Whitson, 1998). Outlining the economic manoeuvrings of sporting and media organisations in detail, the importance of television is regularly stressed as a key site of engagement with professional sport (Rowe, 2004, 2011). Broadcast deals with sporting organisations are a substantial income stream for participating clubs and rights deals with traditional broadcasters have been increasing despite the shift towards a post-broadcast age. For example, the Australian Football League sold the free to air, subscription and online rights to their matches from 2012 - 2016 for a record AU\$1.25 billion (Goldsmith, 2013).

Recent research has productively assessed how the televisual spectacle of sport has continued to operate amidst the instabilities of the post-broadcast era. Ben Goldsmith notes that the major television networks have managed to negotiate this landscape by protecting their central role in the delivery of sport content while also distributing content in innovative ways:

Sports coverage and related content continues to undergird and sustain traditional forms of television, while simultaneously drawing viewers online and promoting sales of High Definition, 3D and 'smart' or 'connected', internet enabled television sets, thus ensuring that television remains at the heart of the digital media-sports-cultural complex (Goldsmith, 2013: 53).

Brett Hutchins and David Rowe have also conducted important research investigating the digital turn, calling on researchers to move away from a broadcast-centric model and take into account the use of social media by sporting celebrities, the ease with which fans can access increasingly abundant sporting content, and the different corporate interests and 
investments that come to the fore in this new digital environment (Hutchins and Rowe, 2009, 2012).

An emphasis on high-quality and high-tech innovation is present in critical discussions around sports media and its future role in a post-broadcast era. This tendency is evident in references to the introduction of High Definition, 3D and internet enabled television (as quoted above from Goldsmith, 2013), the increased importance of mobile television and tablets as a content delivery platform (Hutchins, 2014), the ability of 'associations, clubs, athletes, and individual users' to 'transmit quality digital content and footage' (Hutchins and Rowe, 2009: 264), and the use of social media as alternative sites for the circulation of sports content (Pegorago \& Clavio, 2010; Sanderson, 2013). These new technologies are clearly important in re-configuring the current media landscape, but in ways that can be uneven, contested and unintentional. Such recurring narratives draw attention to the dimensions of media sport, and media cultures in general, that are technologically 'new', digitalised, and significantly driven by industry investments and actions (see also Pertierra and Turner, 2013).

This tendency is consistent with how selected media sport scholars have approached audiences in the past. It is important to note that media sport scholarship has accounted for various dimensions of sports fandom (see Guilianotti 2002; Rowe, 1995; Williams, 2007), as well as the increasing importance of media audiences over local fans (see Jhally, 1984; Sandvoss, 2003). However, the study of fandom and consumption is still often connected to a broader political economic framework that attends to issues surrounding the globalisation of media sport. A political economy approach sheds helpful light on our everyday engagements with media sport and its markets, but it is not primarily concerned with exploring quotidian media practices in-depth. Therefore, we contend that the everyday experiences and practices 
of sports media audiences require greater attention. This approach promises to reveal the intricacies of how sports media is consumed, as well as how everyday consumption practices contribute to the shaping of broader political and economic infrastructures of media sport.

\section{A practice-oriented approach to media sport}

It is important to track and analyse institutional changes and the economic alliances that structure the commercial media industry, but as Pertierra and Turner argue:

What television now does - how it's imbricated into the practices of everyday life, what kinds of social and cultural functions it can perform, and how it participates in the construction of communities - has been much less explored (2013: 10).

More needs to be known about how sports media consumers navigate between multiple media platforms (old and new), proliferating sports media content (with YouTube, for example, emerging as an archive of authorised and user-created sports clips), and how people's daily media routines and practices influence existing markets and regulatory frameworks. We suggest that the recent turn towards practice in media studies provides a set of conceptual tools to think about and analyse these issues.

Practice theory rests on a significant history of social theory that attempted 'to liberate agency [...] from the constrictions of structuralist and systemic models, while avoiding the trap of methodological liberalism' (Postill, 2010: 7). The notion of practice has been used in a number of ways (see, for example, Bourdieu, 1984; de Certeau, 1984; Giddens, 1984), but all 'share a common interest in emphasizing routines, shared habits, technique and competence' (Shove and Pantzar, 2005: 44). To focus on practice means to focus on the body as a 'nexus of arrays of activities' (Postill, 2010: 11) and to view routine and habit as forms of agency that 
have the power to influence natural and social worlds. Such a focus on the body and materiality calls on media researchers to move away from positivist foundations and instead consider the everyday habits that constitute social life.

A practice approach demands that media be viewed beyond 'objects, texts, apparatuses of perception or production processes' and instead focus on 'what people are doing in relation to media in the contexts in which they act' (Couldry, 2012: 35). Nick Couldry (2012: 17) notes that 'describing what people do with media used to be simple: watching a documentary program; following a radio serial; reading weekly magazines or daily newspapers; going to the cinema to see a film; turning the pages of a book'. However, the 'inherent' uncertainty and complexity of digital media has led to a destabilisation of media practice, and the new regimes of habit that form in these ecologies are yet to be properly understood (Couldry, 2012: 17). Therefore, studying practice becomes an increasingly important avenue through which to contextualise and understand the contemporary media environment. Thus, we can approach media - and for the purposes of this paper, media sport - as something that is constituted and defined by institutional structures, but which is also significantly determined by the habits, social networks and 'patterns in the lives of those who watch it' (Pertierra and Turner, 2013: 16).

\section{The audience member as distributor and broadcaster: contemporary media sport practices}

Traditional norms of broadcast television programming, advertising and viewing have been challenged by a range of innovative online services and devices ushering in the postbroadcast era of television (Turner and Tay, 2009). Post-broadcast television is typified by content circulating on a range of devices, incorporating social media integration and flexible time shifting and space shifting. However, users are engaging with these technologies in a 
range of sophisticated ways, often challenging institutional attempts to regulate and organise the post-broadcast space. Media sport stands as something of a paradigmatic case in this area, due to the complex international licensing arrangements [that] continue to limit the development of comprehensive live and on-demand streaming services' (Bruns, 2009: 2). While traditional sports broadcasting remains at the forefront of televisual innovation, the content itself is often restricted to particular regions or nations. Subsequently, media sport audiences have engaged in a range of emergent media practices in order to access and distribute sporting content, seeing the user emerge as both (post-) broadcaster and distributor (see Bruns, 2009; Burroughs and Rugg, 2014).

One popular strategy involves an individual purchasing direct access online content such as 'league' and 'game' passes, and then sharing their username and password with friends or family. League passes are popular methods of distribution for North American competitions such as the National Basketball Association (NBA) and the National Football League (NFL) in the post-broadcast sphere, as they allow consumers to subscribe to content directly from the organisation (NBA, 2013a, NFL 2013a). Such passes provide consumers with a season's worth of access, and the ability to watch live in-season games or archival footage from any desktop, mobile or laptop connected to the Internet. Games can be streamed in High Definition and the normative value of quality - expected to be predominant in consumers' minds - is clearly present in the framing of these passes. For example, the webpage for the NBA league pass advertises the 'Ultimate NBA Game Experience' and tells sporting fans that they'll 'never miss a shot' (NBA, 2013a).

Sports audiences are well acquainted with the strategy of sharing NBA and NFL league passes with friends, family and even strangers. In the purchasing of subscriptions and sharing of passwords between these networks, there is a clear economic incentive to defray the cost of 
such subscriptions even though such acts contravene the agreed terms of service agreed to by users (NBA, 2013b; NFL, 2013b). However, it must be noted that these strategies are not costfree and the advertised benefit of access to NBA or NFL anytime and anywhere is immediately limited. Despite sharing passwords, these accounts can still only be accessed by one user at a time, meaning that constant negotiation between various parties is required throughout the season. In order to engage in this practice, each person must be willing to give up the promise of unlimited access in place of an economic and socially strategic management of the account. We suggest that these sacrifices are about more than saving money and personal finances. These shared practices generate a turn towards a negotiated engagement with the sports media that emphasises the communal sharing of resources, meaning that these liminal user practices involve more than just alleged acts of media piracy.

The sharing of the NBA league pass is a banal but illuminating example. Accusations of poor customer engagement and technical difficulties plaguing the service (see Marchman, 2013) are possible reasons why people look to split the cost of the league pass with other likeminded fans. Indeed, popular social networks and online forums dedicated to basketball see fans inquiring about sharing league passes with friends and family. In response to a post on social news network Reddit about the possibility of sharing a league pass, user 'LGom09' notes, 'You could probably share the username and password with as many people as you wanted. My brother and I did this last year'. 'anthonymi' also chimes in and says that he 'split it with a friend in college', but once they both left campus and moved to different areas 'it stopped working for both of us' (Is it possible to split an NBA League Pass, 2013).

In team-specific online forums, this socially oriented sharing of the league pass also occurs, but at one remove. While the sharing of passes generally occurs between friends and family members in materially oriented social networks, the close online relationships that exist 
between online fan forum members extends to participating in media practices together. In the online forum 'ClutchFans', dedicated to the NBA team Houston Rockets, a thread is begun entitled 'Can you share NBA League Pass Broadband?' However, this initial thread is quickly derailed by 'AB83Rules', who offers his league pass to forum users: 'If anyone needs access, let me know, I have the [League Pass] for TV on DirecTV and have the Broadband [ ... ] Works good. let me know' (sic). Forum users responded quickly and by the next day only two spots were left, with 'AB83Rules' noting that he would only 'do a total of 7 people and that is it. I have done 5 so far' (Can you share NBA League Pass Broadband, 2011). This example outlines the complex relationships that exist between media sport users, and that these media practices involve elements of sociality that encompass friendship, family relationships and fandom.

Another popular media practice sees users live-streaming content by engaging in 'guerrilla rebroadcasting' of sporting content through online services like Justin.tv (Bruns, 2009; see also Birmingham and David, 2011). Justin.tv allows individual users to 'stream content live to its servers for immediate re-broadcast' and also archives these DIY broadcasts for 'later ondemand viewing' (Bruns, 2009). These features saw Justin.tv become the favoured online platform for the 're-broadcasting of mainstream television content' for a number of years and a range of international sports featured on this website, driven by 'underserved' television populations and diasporic communities across the world (Bruns, 2009). However, aggressive campaigns and a series of lawsuits by a range of copyright holders saw Justin.tv begin to cooperate with rights holders (see Birmingham and David, 2011; Rice, 2012). As a result the website's popularity has fallen with its audience, which 'Quantcast pegged at around 20 million visitors in March 2010 ... falling about 20\% over the following year' (Rice, 2012). 
The audience-driven live streaming of sports has dispersed after a brief period of upstart monopolisation by Justin.tv. However, a range of platforms and services still allow users to continue these practices, either by re-broadcasting through webcams or directly linking a cable box to their computer (Rice, 2012). As a re-broadcaster explains in an interview with Mark Zeigler (2013), even after Justin.tv ramped up its enforcement efforts, it has been easy to avoid these strategies:

Occasionally the leagues or TV networks would find his streams, file Digital Millennium Copyright Act takedown notices with the hosting website, and his computer screen would go black. He'd shake his head, create a new streaming channel - "It takes a second or two," he says - and post the new link. The game would go live again.

When the leagues began using digital fingerprinting and automated takedown tools to instantly remove streams from hosting websites in the United States, he switched to websites located elsewhere - in Pakistan or China or the Netherlands, wherever intellectual property rights laws are lax or laxly enforced.

The initial popularity of Justin.tv has made it harder to regulate and stop user re-broadcasting, with a suite of services and strategies now available to 'guerrilla re-broadcasters' (Bruns, 2009) operating across the globe.

In a similar fashion to the sharing of purchased league passes above, we note that this strategic re-purposing of institutional distribution streams involves sacrificing a level of quality. Live streams are a poor quality substitute compared to an official broadcast, regularly dropping out or freezing, featuring single language commentary while broadcasting to a global audience, and presenting footage of comparatively low quality when compared to cable television. Of course, many of these live feeds host matches from globally popular sporting leagues such as the English Premier League (EPL) or the NBA. However, these feeds also host a range of lower-profile matches that do not receive widespread coverage, such as minor tennis tournaments, the youth teams of professional football teams, and football league 
matches from small leagues across Europe. Subsequently, these re-broadcasts stand as a parallel form of curation and distribution for a globalised sporting audience that is willing to sacrifice quality for access to games that are covered by major broadcasters.

\section{The implications of a practice-based approach for the study of media sport}

The examples of media practice presented above offer an alternative snapshot of the sports media landscape, one that is grounded in people's everyday engagements with media and connected to habits, norms, materialities, and literacies. In contrast to the prevailing industry and policy narratives, the emergence and proliferation of new technologies does not presuppose either linear technological progress or an automatic increase of audience engagement with high-quality content. Instead, we see users engage in a range of mundane habits and practices that negotiate the values of material quality (of media production and delivery) alongside other motivations including categories of access, experience and sociality. The emergent conceptualisations of 'polymedia' (Madianou and Miller, 2013) or 'transmedia' (Jenkins, 2010) that seek to tease out existing configurations of media practices across multiple media platforms stand as welcome contributions to sports media and offer an additional conceptual frame through which to understand engagement with sports content.

The critical aspect of the practice-oriented argument is the fact that complex media sport practices both derive from and shape the various routinised, affective and quotidian elements of everyday life. Table 1 presents a heuristic tool that outlines the differences between a practice and institutionally oriented approach. The categorical contrasts displayed in Table 1 add nuance to existing approaches to the study of media sport and seek to offer an account that contextualises the irrational and unintended ways in which media practice is encountered, enacted and valued in everyday life. 


\section{Insert Table 1 here}

This table underlines the contingency and specificity of media practice. This stance echoes an argument that has been made previously in various social histories of media evolution, which highlight the persistence of ageing media in the face of obsolescence and the complex coexistence of old and new media (see Gitelman, 2006; Bolter and Grusin 2000; Couldry, 2012). This contingency draws attention to existing practices, revealing the multiple 'cracks' that remain in media systems, and underlines the various resources and literacies that people mobilise to navigate their way through them. The popular appeal of sport provides a persistent incentive for industries and markets to adapt to and innovate in this space. However, the examples presented in the previous section underline the necessity of situating media practice within a specific context, allowing us to locate actual consumption processes. This approach seeks to avoid an implicit treatment of sports media and consumers as 'an effect of technology, geography, politics or the market' (Pertierra and Turner, 2013: 8).

An analysis of media practice also opens up new avenues for understanding innovation. Media sport has a long history as a significant site of media innovation. Over the years broadcast organisations have deployed inventive camerawork, introduced High Definition television (HD) and even 3D television in order to distinguish sports content, which is often seen as central to a television network's identity (see Goldsmith, 2013; Rowe, 2004). However, practice theory presents an alternative narrative of innovation that underlines the importance of consumers in the innovation process. As practice theorists Elizabeth Shove and Mika Pantzar (2005: 45) outline, innovation relies on a 'dynamic, but interdependent, relationship between practitioners and providers'. Recognising this theoretical position requires acknowledgement that both producers and consumers are involved in establishing practices and sustaining new technologies and products (Shove and Pantzar, 2005). We are not 
claiming that these media practices themselves are innovative, but are suggesting that the strategic negotiation of institutionally authorised distribution models has a subsequent impact on the formation of media sport markets, consumer practices, and 'bottom-up' innovation strategies.

Describing and theorising these media practices is an important step in mapping new empirical territory. It begins the process of producing a more fine-grained account of how innovation takes place across the macro and micro spheres of sports media practice. As Bruns (2014: 16) notes, 'Sometimes it is society and sometimes the media that drive processes of innovation and change, but both are inextricably interdependent on each other.' Therefore, it is imperative that we examine 'innovative practices of participating in society ... itself' (Bruns, 2014: 19). Media practices are, therefore, a central site from which to study innovation through the intricate interaction of technological systems, social relations, and culture.

\section{Conclusion}

This paper has presented a way to complement the current political economic accounts of the literature on sports media. Embracing a recent turn towards 'practice' within cultural and media studies (Couldry, 2012; Pertierra and Turner, 2013; Postill, 2010), we have outlined a conceptual framework that takes into account an array of quotidian practices surrounding media sport consumption and innovation. Our initial conceptual attempt to understand these practices in the context of existing scholarly work and current media practices allows us to revisit the concepts of quality, innovation and access. This framework provides an important reminder about the generative nature of these bottom-up practices and shows that everyday forms of interaction with media can influence macro-structures such as markets and function as a dynamic site where innovations are tested and enacted. Much in the same way that a political economy approach offers a particular conceptualisation of media audiences, a 
practice-led approach offers an alternative account of institutions and their interactions with trajectories of innovation and media audiences. Looking ahead, further qualitative and quantitative research centred on everyday media practices will help to provide greater detail regarding the broad conceptual outline that we have provided here, creating a basis for a deeper understanding of the everyday lives of media users and the sports media practices they create and perpetuate. 


\section{References}

Birmingham J and David M 2001, 'Live-streaming: will football fans continue to be more law abiding than music fans?' Sport in Society, vol. 14, no. 1, pp. 69-80.

Bolter J and Grusin R 2000, Remediation: Understanding New Media, MIT Press, Cambridge.

Bruns A 2009, 'The user-led disruption: self-(re)broadcasting at Justin.tv and elsewhere' , in Geerts, D, Cesar, P, \& De Grooff, D (Eds.) EuroITV '09: Seventh European Interactive Television Conference, 3-5 June 2009, Leuven, Belgium.

Bruns A 2014, 'Media innovations, user innovations, societal innovations', Journal of Media Innovations, vol. 1, no. 1, pp. 13 - 27.

Bourdieu P 1984, Distinction: A social critique of the judgment of taste, Routledge, London.

Burroughs B and Rugg A 2014, 'Extending the Broadcast: Streaming Culture and the Problems of Digital Geographies'. Journal of Broadcasting \& Electronic Media, vol. 58, no. 3, pp.365-380.

'Can you share an NBA League Pass Broadband', ClutchFans: The BBS, Available from http://bbs.clutchfans.net/showthread.php?t=212084, viewed 24 April 2014.

Couldry N 2004, 'Theorising media as practice', Social Semiotics, vol. 14, no. 2, pp. 115-132.

Couldry N 2012, Media, society, world: Social theory and digital media practice. Polity, Cambridge.

de Certeau M 1984, The Practice of Everyday Life, University of California Press, Berkley.

Giddens A 1984, The constitution of society: introduction of the theory of structuration, University of California Press, Berkley.

Gitelman L 2006, Always already new: Media, history and the data of culture, MIT Press, Cambridge.

Giulianotti R 2002, 'Supporters, followers, fans and flaneurs: a taxonomy of spectator identities in football', Journal of Sport and Social Issues, vol. 26, no. 1, pp. 25-46.

Goldsmith B 2013, "SporTV": the legacies and power of television', in: Hutchins, B \& Rowe, D (eds) Digital Media Sport: Technology, Power and Culture in the Network Society, Routledge, London and New York, pp. 52-65.

Hartley J and McKee A 2000, The Indigenous Public Sphere: the reporting and reception of Indigenous issues in the Australian media, 1994-1997, Oxford University Press, Oxford.

Hutchins B 2014, 'Sport on the move: The unfolding impact of mobile communications on the media sport content economy' Journal of Sport \& Social Issues, 38(6): 509-527.

Hutchins B \& Rowe D 2009, 'From Broadcast Scarcity to Digital Plenitude The Changing Dynamics of the Media Sport Content Economy', Television \& New Media, vol. 10, no. 4, pp. 354-370. 
Hutchins B \& Rowe D 2012, Sport Beyond Television: The Internet, Digital Media and the Rise of Networked Media Sport, Routledge, New York.

'Is it possible to split an NBA League Pass?' Reddit: NBA, available at http://www.reddit.com/r/nba/comments/1lixua/is_it_possible_to_split_an_nba_league_pass/ , viewed 24 April 2014.

Jhally S 1984, 'The spectacle of accumulation: Material and cultural factors in the evolution of the sport/media complex', Insurgent Sociologist, vol. 12, no. 3, pp. 41-57.

Jenkins H 2010, 'Transmedia storytelling and entertainment: An annotated syllabus', Continuum: Journal of Media \& Cultural Studies, vol. 24, no. 6, pp. 943-958.

Madianou M, and Miller D 2013, 'Polymedia: Towards a new theory of digital media in interpersonal communication', International Journal of Cultural Studies vol. 16, no. 2, pp. 169187.

Maguire J 1993, 'Globalization, sport development, and the media/sport production complex', Sport Sciences Review, vol. 2, no. 1, pp. 29-47.

Marchman, T 2013, 'Don't Pay For NBA League Pass Broadband! It's Straight Up Garbage', Deadspin, available at http://deadspin.com/5956559/nba-league-pass-broadband-is-shitand-you-should-not-buy-it/1457644137/@marchman, viewed 24 April 2014.

Marjoribanks $\mathrm{T}$ and Farquharson $\mathrm{K}$ 2012, Sport and society in the global age, Palgrave Macmillan, Houndmills.

McKay J 1991, No pain, no gain? Sport and Australian culture. Prentice Hall, Sydney.

Miller T, Lawrence G, McKay J \& Rowe D 2001, Globalization and sport: Playing the world. Sage, London.

Miller T 2010, Sportsex. Temple University Press, Philadelphia.

NBA 2013a, NBA League Pass. Available at: www.nba.com/leaguepasss, viewed 28 September 2013.

NBA 2013b, NBA Terms of Use. Available at: http://www.nba.com/news/termsofuse.html, viewed 28 September 2013.

NFL 2013a, NFL Game Pass. Available at: gamepass.nfl.com, viewed 28 September 2013.

NFL 2013b, Subscription Products Terms and Conditions. Available at: http://www.nfl.com/help/subscriptions_terms, viewed 28 September 2013.

Pertierra A C and Turner G 2013, Locating Television Today: Zones of Consumption. Routledge: New York.

Pegoraro A \& Clavio, G 2010, 'Look who's talking - athletes on twitter: a case study', International Journal of Sport Communication, vol. 3, no. 4, pp. 501-514. 
Postill J 2010, 'Introduction: Theorising Media and Practice', in: Bräuchler B and Postill J (eds), Theorising media and practice, Berghahn Books, Oxford, pp. 1 - 34.

Rice A 2012, 'The many pivots of Justin.tv: How a livecam show became home to video gaming superstars', Fast Company, available at http://www.fastcompany.com/1839300/manypivots-justintv-how-livecam-show-became-home-video-gaming-superstars, viewed 24 April 2014.

Rowe D 1995, Popular Cultures: Rock Music, Sport and the Politics of Pleasure. Sage, London.

Rowe D 2004, Sport, Culture and the Media: The Unruly Trinity, 2nd edition. Open University Press, Maidenhead, UK.

Rowe D 2011, Global Media Sport: Flows, Forms and Futures. Bloomsbury Academic, London.

Rowe D and Lawrence G 1990, Sport and Leisure: Trends in Australian Popular Culture. London Brace Jovanovich, Sydney.

Sanderson J 2013, 'Social media and sport communication: Abundant theoretical opportunities', in PM Pedersen (ed.), Routledge handbook of sport communication, Routledge, New York, pp. 56-65.

Sandvoss C 2003, A Game of Two Halves: Football, Television and Globalization. Routledge: London.

Shove E and Pantzar M 2005, 'Consumers, Producers and Practices Understanding the invention and reinvention of Nordic walking', Journal of Consumer Culture, vol. 5, no. 1, pp. 4364.

Turner G and Tay J, eds., 2009 Television studies after TV: Understanding television in the post-broadcast era. Routledge: London.

Wenner L ed., 1989, Media, sports, \& society. Sage: Thousand Oaks.

Whannel G 2001, Media sport stars: Masculinities and moralities, Routledge, London and New York.

Whannel G 2008, Culture, politics and sport: Blowing the whistle, revisited, Routledge, London and New York.

Williams J 2007, 'Rethinking Sports Fandom: The Case of European Soccer', Leisure Studies, vol. 26, no. 2, pp. 127-146.

Whitson D 1998 'Circuits of promotion: Media, marketing and the globalization of sport', in L. Wenner (Ed.), MediaSport, Routledge, New York, pp. 57-72.

Zeigler M 2013, 'Piracy: Sports leagues' biggest problem', U-T San Diego, December 30, available at http://www.utsandiego.com/news/2013/Dec/30/nfl-mlb-world-cup-chargerscongress-ncaa-nhl/, viewed 24 April 2014. 
Table 1: Political economic and practice-led approaches to sports media

\begin{tabular}{|l|l|}
\hline Political economic & Practice-led approach \\
media & \\
\hline Macro-level & Micro-level \\
\hline Institutional & Quotidian \\
\hline Technological & Social \\
\hline Formal & Informal \\
\hline Rational & Irrational \\
\hline Future-oriented & Trans-historical \\
\hline Projected & Actual \\
\hline Abstract & \\
\hline
\end{tabular}

